\title{
Prenatal prediction of neonatal haemodynamic adaptation after maternal hyperoxygenation
}

\author{
Ann McHugh ${ }^{1 *}$ (D, Colm Breatnach², Neidin Bussmann², Orla Franklin ${ }^{3}$, Afif El-Khuffash² and \\ Fionnuala M. Breathnach ${ }^{1}$
}

\begin{abstract}
The reactivity of the pulmonary vascular bed to the administration of oxygen is well established in the post-natal circulation. The vasoreactivity demonstrated by the fetal pulmonary artery Doppler waveform in response to maternal hyperoxia has been investigated. We sought to investigate the relationship between the reactivity of the fetal pulmonary arteries to hyperoxia and subsequent neonatal cardiac function in the early newborn period.

Methods: This explorative study with convenience sampling measured pulsatility index (PI), resistance index (RI), acceleration time (AT), and ejection time (ET) from the fetal distal branch pulmonary artery (PA) at baseline and following maternal hyperoxygenation $(\mathrm{MH})$. Oxygen was administered for $10 \mathrm{~min}$ at a rate of $12 \mathrm{~L} / \mathrm{min}$ via a partial non-rebreather mask. A neonatal functional echocardiogram was performed within the first $24 \mathrm{~h}$ of life to assess ejection fraction (EF), left ventricular output (LVO), and neonatal pulmonary artery AT (nPAAT). This study was conducted in the Rotunda Hospital, Dublin, Ireland.
\end{abstract}

Results: Forty-six women with a singleton pregnancy greater than or equal to 31 weeks' gestational age were prospectively recruited to the study. The median gestational age was 35 weeks. There was a decrease in fetal PAPI and PARI following MH and an increase in fetal PAAT, leading to an increase in PA AT:ET. Fetuses that responded to hyperoxygenation were more likely to have a higher LVO $(135 \pm 25 \mathrm{~mL} / \mathrm{kg} / \mathrm{min}$ vs $111 \pm 21 \mathrm{~mL} / \mathrm{kg} / \mathrm{min}, p<0.01)$ and $\mathrm{EF}(54 \pm 9 \%$ vs $47 \pm 7 \%, p=0.03)$ in the early newborn period than those that did not respond to $\mathrm{MH}$ prenatally. These findings were not dependent on left ventricular size or mitral valve (MV) annular diameter but were related to an increased MV inflow. There was no difference in nPAAT.

Conclusion: These findings indicate a reduction in fetal pulmonary vascular resistance (PVR) and an increase in pulmonary blood flow and left atrial return following $\mathrm{MH}$. The fetal response to hyperoxia reflected an optimal adaptation to postnatal life with rapid reduction in PVR increasing measured cardiac output.

Keywords: Hyperoxygenation, Doppler echocardiography, Pulmonary artery Doppler

\footnotetext{
* Correspondence: mchughaf@tcd.ie

1 Department of Obstetrics and Gynaecology, Royal College of Surgeons in Ireland, Rotunda Hospital, Dublin, Ireland

Full list of author information is available at the end of the article
}

C The Author(s). 2020 Open Access This article is licensed under a Creative Commons Attribution 4.0 International License, which permits use, sharing, adaptation, distribution and reproduction in any medium or format, as long as you give appropriate credit to the original author(s) and the source, provide a link to the Creative Commons licence, and indicate if changes were made. The images or other third party material in this article are included in the article's Creative Commons licence, unless indicated otherwise in a credit line to the material. If material is not included in the article's Creative Commons licence and your intended use is not permitted by statutory regulation or exceeds the permitted use, you will need to obtain permission directly from the copyright holder. To view a copy of this licence, visit http://creativecommons.org/licenses/by/4.0/. The Creative Commons Public Domain Dedication waiver (http://creativecommons.org/publicdomain/zero/1.0/) applies to the data made available in this article, unless otherwise stated in a credit line to the data. 


\section{Background}

In utero, the placenta functions as the organ for gaseous exchange [1]. A high pulmonary vascular resistance (PVR) is a normal state for the fetus and pulmonary vascular tone increases with advancing gestational age (GA) [2]. Fetal pulmonary arterial vascular impedance decreases during the second half of pregnancy until 34 to 35 weeks GA [3]. Despite ongoing lung growth after 34 to 35 weeks' gestation, the pulmonary vascular impedance thereafter remains unchanged [4]. At $\geq 37$ weeks gestation, pulmonary blood flow increases substantially to almost half of the right ventricular output [5]. A low oxygen tension environment exists in utero, which promotes high intrinsic myogenic tone and high vasocontractility [6]. At birth, there is a reduction in pulmonary arterial pressure and resistance, due to an increase in oxygen tension and up to a ten-fold rise in pulmonary blood flow [6]. Neonatal survival is dependent upon a rapid, complex and well-orchestrated transition from the intra- to extrauterine environment [7]. Normal transition to newborn circulation requires high fetal pressures to fall, with dilatation of the pulmonary vessels. Previous studies have indicated that the capacity of pulmonary arteries to dilate can be judged prenatally, by administering high-dose oxygen to the mother [8-10].

\section{Hyperoxygenation}

Studies have shown that fetal pulmonary vasculature reacts to maternal hyperoxygenation $(\mathrm{MH})[4,11,12]$. Oxygen induces the release of several vasodilators including endothelium-derived nitric oxide and prostacyclin, resulting in a decrease in PVR and an increase in pulmonary blood flow [13]. Following maternal oxygen administration, a decrease in the fetal PVR, as demonstrated by the pulmonary artery (PA) Doppler, is deemed to indicate vasoreactivity in the pulmonary vascular bed [14]. The reactivity of the PA to changes in fetal oxygen tension can be detected by noninvasive Doppler ultrasound techniques between 31 and 36 weeks GA [4]. Nomograms of pulmonary reactivity induced by hyperoxia during gestation have been established [13]. The measurement of pulmonary velocity waveforms before and after $\mathrm{MH}$ may therefore help in predicting how the fetus will adapt to the extra-uterine environment and transition to neonatal life. If there is a failure of the normal circulatory transition in the early newborn period, persistence of the fetal circulation occurs, resulting in pulmonary hypertension, low oxygen levels and may result in right-to-left shunting of blood in the newborn heart [2]. Some degree of pulmonary hypertension complicates the course of more than $10 \%$ of all neonates with respiratory failure [15]. Approximately 10\% of neonates will require some form of clinical intervention at birth with $1 \%$ requiring more extensive resuscitation [16]. It is vitally important for clinicians to understand the changes that occur during the transition to neonatal life and to predict which neonates may have difficulty transitioning [16]. Prediction of neonatal pulmonary hypertension may influence the delivery planning for particularly high-risk cases and help guide the pharmacological and neonatal intensive care strategies that optimise postnatal survival. The ability to predict the fetal transition to neonatal life by a method that is non-invasive and reproducible would be beneficial for obstetric management, for parental counselling and for determining optimal neonatal management.

In this explorative prospective study, we hypothesise that the degree of the fetal pulmonary vascular bed response to maternal hyperoxia assessed using pulmonary artery Doppler ultrasound at $\geq 31$ weeks' gestation can predict transition during the early neonatal period.

\section{Study objective}

To evaluate changes in the fetal pulmonary artery Doppler following maternal hyperoxygenation during the third trimester of pregnancy and to correlate those findings with neonatal echocardiograph indices indicative of increased pulmonary systolic pressures, including estimates of right ventricular systolic pressures, PA acceleration time in addition to measurements of neonatal ejection fraction and left ventricular output.

\section{Methods}

This explorative prospective pilot study was undertaken in the Department of Obstetrics and Gynaecology in the Rotunda Hospital Dublin, Ireland between January 2017 and July 2018. The Rotunda Hospital is a tertiary-level, stand-alone maternity hospital in Dublin, Ireland, with over 8500 deliveries per year. The Maternal Fetal Medicine and Neonatology departments accept national referrals and have over 1500 admissions to the neonatal unit per year. The study was approved by the National Research Ethics Committee of the National Maternity Hospital and by the Health Products Regulatory Authority in Ireland. Pregnant women who had attained a minimum GA of 31 weeks and up to 40 weeks were recruited to the study. The patients were recruited through the prenatal department in the hospital. If deemed eligible, subjects were approached by the lead study investigator and invited to take part in the study. Inclusion criteria were as follows: age $\geq 18$ years with no significant medical history. Participants with a non-smoking status were chosen given the hazards associated with smoking and high flow oxygen [17] and to eliminate any effect that smoking may have on Doppler velocity waveforms [1820]. Singleton pregnancies with a normally grown fetus (estimated fetal weight $\geq 5$ th centile and $\leq 95$ th centile for GA) were included, this was to exclude any effect 
that growth restriction [21-23] or fetal macrosomia [24, $25]$ may have on fetal Doppler waveforms. Fetuses $\geq 31$ weeks' gestation were included as the hyperoxygenation test is known to become responsive after this GA [4]. Those with a GA $>40$ weeks were excluded given the potential for advanced GA to affect the acquisition of or the result of various Doppler indices. A window of 31-40 weeks GA was chosen to increase uniformity and to acquire better data. Additional exclusion criteria included known fetal chromosomal abnormality, use of bleomycin or amiodarone, current use of nitrofurantoin or use within the last 7 days as interactions can occur between these drugs and oxygen, use of any pre-existing vasoactive medication that could affect cardiac function, or those unable to provide written informed consent. Limited data exist on the haemodynamic changes in pregnancy in response to $\mathrm{MH}$ [26] and for this reason we excluded those with any chronic respiratory disease, congenital heart disease or uncontrolled diabetes. Baseline characteristics of all women were recorded and included maternal age, GA, gravidity, body mass index (BMI) and antepartum haemoglobin.

\section{Study procedures}

Image-directed pulsed and colour Doppler equipment (Voluson E8) was used with a $5-\mathrm{MHz}$ sector probe. All Doppler recordings were obtained using the lowest high-pass filter level $(100 \mathrm{~Hz})$, and the spatial peak temporal average power output for colour and pulsed Doppler was kept at $<100 \mathrm{~mW} /$ $\mathrm{cm}$ [27]. An angle of $\leq 15^{\circ}$ between the vessel being studied and the Doppler beam was deemed acceptable and used for analysis. All participants underwent a standard ultrasound examination for estimation of fetal weight, amniotic fluid volume measurements, fetal heart rate and umbilical (UA) and middle cerebral artery (MCA) Doppler assessment. A fetal echocardiogram was performed according to the International Society of Ultrasound in Obstetrics and Gynecology (ISUOG) guidelines for fetal echocardiography [28] on fetuses between 31 and 40 weeks gestation. This involved a sequential segmental analysis of the atria, ventricles, and great arteries and their connections. Specific echocardiographic Doppler studies included those of the distal main PA and ductus arteriosus (DA) (Figs. 1 and 2). The following measurements specific to the PA Doppler waveform were recorded: The peak systolic velocity (PSV), end diastolic velocity (EDV), timeaveraged velocity (TAV), pulsatility index (PI), resistance index (RI), ejection time (ET) and acceleration time (AT). The ductus arteriosus waveform was obtained in the traditional longitudinal ductal arch view. Reported values were averaged from three consecutive waveforms. Oxygen was administered to the subjects while in a semi-recumbent position in the hospital ultrasound department, at a rate of $12 \mathrm{~L} /$ min for a duration of $10 \mathrm{~min}$ via a partial nonrebreather mask. Immediately following $\mathrm{MH}$, a repeat fetal echocardiogram was performed, and all Doppler recordings were repeated. Each fetus served as its own control. Recordings were stored on the ultrasound machine for further analysis and for data safety monitoring purposes. The hyperoxygenation test was considered positive when the PI of the fetal PA decreased by $\geq 10 \%$ from its baseline (responders). Where the fetal PA PI did not decrease by at least $10 \%$, cases were classified as nonresponders. The fetal PA Doppler measurements were kept in a specific study file and not in the

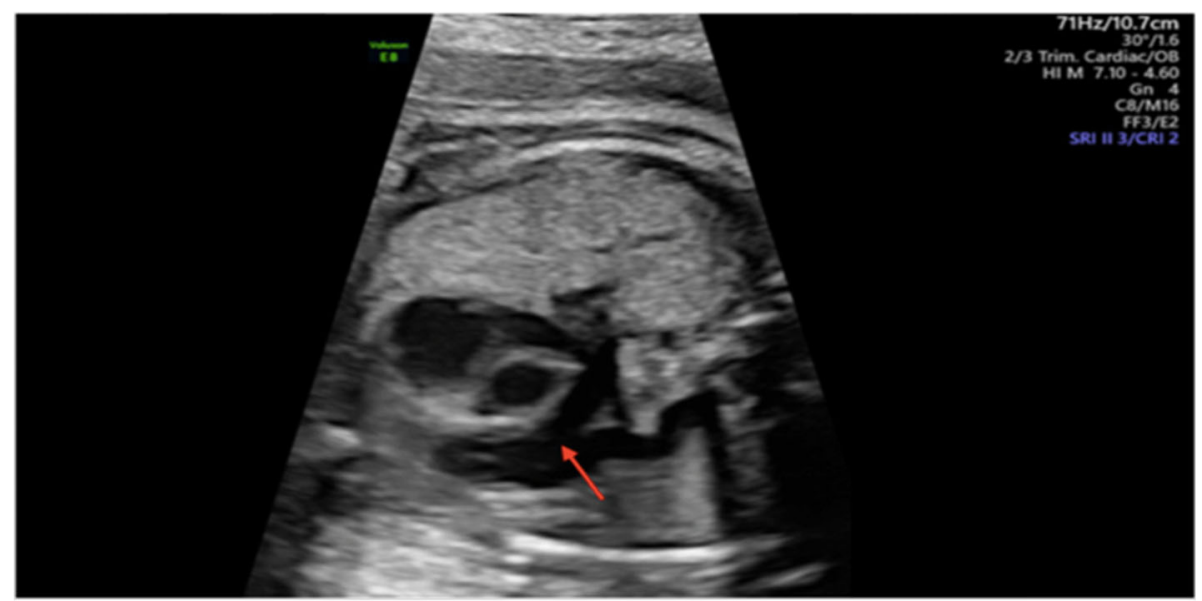

Fig. 1 Ultrasound image of the fetal branching pulmonary artery in an extended three vessel view. The red arrow marks the area where the Doppler velocimetry waveform was obtained 


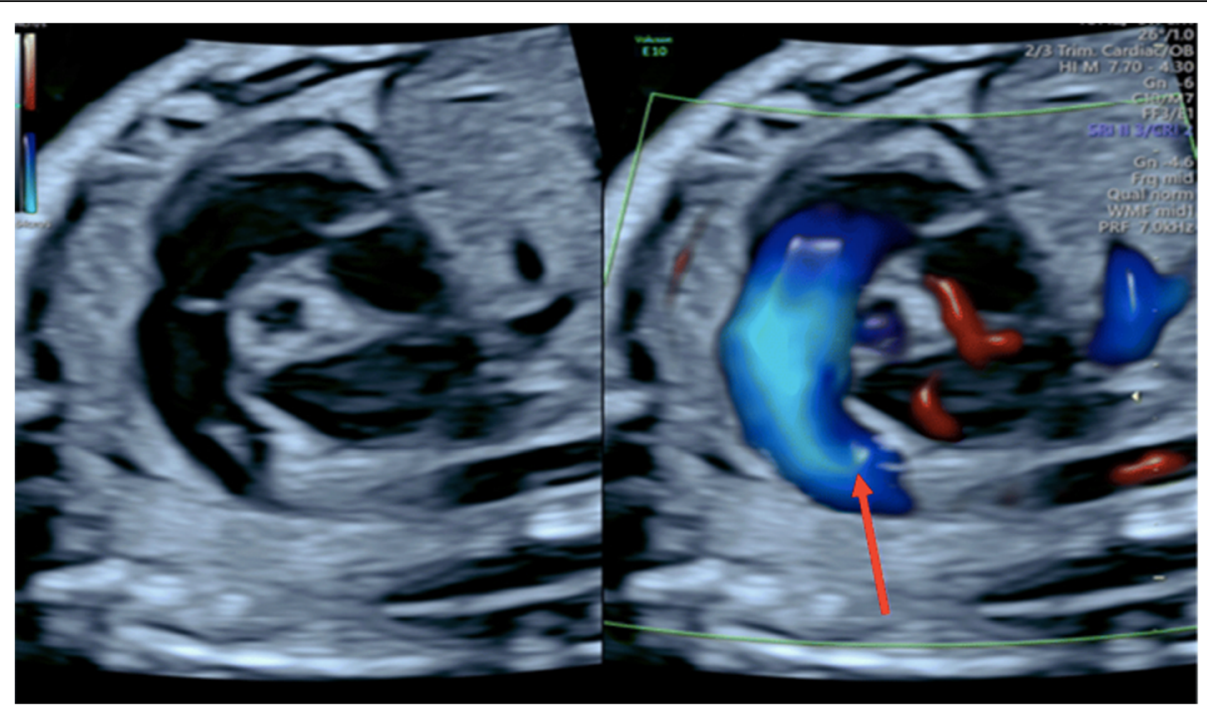

Fig. 2 The pulmonary artery as illustrated in this ultrasound image, arises from the anteriorly positioned right ventricle and courses towards the descending aorta. The ductal arch has a nearly perpendicular shape and resembles a hockey stick. The red arrow represents where the ductus arteriosus Doppler waveform was obtained

subject's hospital file. The calculation of fetal PA reactivity was performed after the ultrasound assessment, when the subject had left the ultrasound room. The subject was not made aware of the prenatal PA reactivity results.

A functional neonatal echocardiogram was performed within the first $24 \mathrm{~h}$ of life. Neonates were divided into those that responded to $\mathrm{MH}$ in utero (responders) and those that did not respond (non-responders). Echocardiography was carried out using a Vivid S6 echocardiography machine and a $7 \mathrm{MHz}$ neonatal probe (GE Medical, Milwaukee, USA). Studies were conducted during a resting state in accordance to recent guidelines and congenital heart disease was excluded during the first scan [29]. Data were stored as raw DICOM images in an archiving system (EchoPac, General Electric, version 112 revision 1.3) and analysis of all the echocardiography parameters was carried out by a single investigator who was blinded to the results of fetal Doppler ultrasounds (N.B). The following echocardiography parameters were also measured using previously described methods [30], left ventricular (LV) length measured at end diastole; mitral value annual diameter; left ventricular output ( $\mathrm{LVO}, \mathrm{ml} / \mathrm{kg} / \mathrm{min})$; ejection fraction using Simpson's Biplane method (EF, \%); mitral valve inflow velocities and velocity time index, patent ductus arteriosus (PDA) diameter ( $\mathrm{mm}$ ) measured in 2D at the pulmonary end; diastolic and systolic flow velocity across the PDA; flow pattern across the duct; pulmonary artery acceleration time (PAAT); and right ventricular (RV) end systolic pressure measured using the tricuspid valve regurgitant jet.

\section{Sample size and statistical analysis}

Sample sizes of between 24 and 50 have been recommended variously for pilot studies [31-38]. Following these recommendations, we chose a recruitment sample size of 40-60 which would allow for a moderate dropout rate. A significant dropout rate (e.g. 40\%) would reduce the pilot sample size to below a minimum of 24 , in which case a possible larger study would be called into question in the first place, having possible external validity issues, pragmatic or ethical concerns. Data analysis was performed using SPSS software (version 24.0; IBM Corporation, Armonk, NY). Continuous data were expressed as means and standard deviations or medians and interquartile ranges as appropriate. Independent data were compared using the independent Student ttest or the Mann-Whitney U test as appropriate. Paired data were compared using the paired Student t-test or the non-parametric equivalent as appropriate. Categorical data were compared using the Chi Square test or the Fisher Exact test. Data were deemed statistically significant at a $p$-value $<0.05$.

\section{Reproducibility bias}

Intraobserver and interobserver variability of fetal PA Doppler indices were assessed using a subset of $10 \mathrm{pa}-$ tients. One reader (A.M) repeated measurements at a time temporally remote from the initial assessment. To assess interobserver variability, a second reader (F.B), blinded to the original data, repeated PA Doppler measurements. Intraobserver and interobserver variability was assessed by calculation of mean percent error, defined as the absolute difference between observations divided by the mean of 
observations and using the intraclass correlation coefficient (ICC) and 95\% confidence intervals (95\% CI). To assess the repeatability of the measured values, the mean and SD of differences and the repeatability coefficient of the two repeated tests within subjects were calculated. The PA Doppler indices that are reported in the results were taken by a single operator (A.M). The study was not powered as a predictive tool and therefore results may not be reflective of a cause and effect relationship.

\section{Results}

Forty-six women in the third trimester were prospectively recruited to the study. Fetal standard anatomical survey did not reveal any structural abnormalities. The mean maternal age was $32.5 \pm 6.2$ years. The median GA at the time of the MH test was 35 [IQR 33-37] weeks (Table 1). Each fetus was appropriately grown for GA (all between the 10th and 90th percentile growth curve). The mean estimated fetal weight was $2660 \mathrm{~g} \pm 626 \mathrm{~g}$ at the time of the sonographic assessment. In all cases, amniotic fluid volumes based on a single deepest vertical pool were within the normal range $(4.8 \mathrm{~cm} \pm 1.8 \mathrm{~cm})$. Successful acquisition of PA Doppler indices were achieved in all participants. A decrease in fetal PA PI was observed following maternal hyperoxygenation, with a median decrease of $21 \%$ [9-36] from the baseline. The resistance index of the PA decreased following $\mathrm{MH}$ (Table 2). There was an increase in PA AT leading to an increase in PA AT:ET, indicating a fall in pulmonary vascular resistance, following $\mathrm{MH}$ (Fig. 3). No changes were observed in the pulsatility indices of the UA or MCA following hyperoxygenation (0.96 to $0.99, p=0.95$ and 1.70 to $1.72, p=0.98$ ), respectively. The fetal reactivity, as demonstrated by the PA PI Doppler measurements in responders and non-responders, was not associated with maternal age $(31.7 \pm 6.4$ years vs. $33.8 \pm$

Table 1 Patient demographic data

\begin{tabular}{ll}
\hline Basic Demographic data $(\boldsymbol{N}=\mathbf{4 6})$ & \\
\hline Age (years) & $32.5 \pm 6.2$ \\
Gestational age (weeks) & $35[33-37]$ \\
BMI $\left(\mathrm{kg} / \mathrm{m}^{2}\right)$ & $30 \pm 5.4$ \\
Nulliparous & $18(39 \%)$ \\
Caucasian & $37(80 \%)$ \\
Indian/Pakistani/Bangladesi & $5(11 \%)$ \\
African & $4(9 \%)$ \\
Haemoglobin in third trimester $(\mathrm{g} / \mathrm{dL})$ & $11.9 \pm 0.92$ \\
Baseline maternal blood pressure $(\mathrm{mmHg})$ & $\mathrm{SBP} 121 \pm 17$ \\
& $\mathrm{DBP} 78 \pm 10$
\end{tabular}

BMI Body Mass Index; $\mathrm{kg} / \mathrm{m} 2$ kilograms per metre squared; $\mathrm{g} / \mathrm{dL}$ grams per decilitre; $\mathrm{mmHg}$ millimetres of mercury; $S B P$ systolic blood pressure; $D B P$ diastolic blood pressure.

Values displayed as mean $\pm S D$, median and [IQR] and percentages (\%).
Table 2 Doppler changes before and after $\mathrm{MH}$

\begin{tabular}{llll}
\hline Doppler measurements & Pre $\mathbf{M H}$ & Post $\mathbf{M H}$ & $\boldsymbol{p}$-value \\
\hline PA PSV cm/s & $60.62 \pm 11.4$ & $59.2 \pm 14.1$ & 0.60 \\
PA EDV cm/s & $7.75 \pm 2.2$ & $8.01 \pm 2.1$ & 0.56 \\
PA TAV cm/s & $16.18 \pm 2.5$ & $18.61 \pm 4.9$ & 0.004 \\
PA PI & $2.47 \pm 0.36$ & $2.08 \pm 0.33$ & 0.0001 \\
PA RI & $0.86 \pm 0.05$ & $0.78 \pm 0.09$ & 0.0001 \\
PA TVI cm & $5.3 \pm 2.1$ & $6.2 \pm 1.7$ & 0.026 \\
PA AT ms & $43[40-47]$ & $57[47-60]$ & 0.005 \\
PA ET ms & $177[163-183]$ & $187[177-207]$ & 0.005 \\
PA AT:ET & $0.25[0.24-0.28]$ & $0.32[0.26-0.34]$ & 0.005 \\
DA PSV cm/s & $106.8 \pm 15.4$ & $109.1 \pm 16.7$ & 0.47 \\
DA EDV cm/s & $12.4 \pm 1.8$ & $11.9 \pm 2.2$ & 0.24 \\
DA TAmax cm/s & $34.4 \pm 7.1$ & $36.4 \pm 6.9$ & 0.18 \\
DA PI & $2.41 \pm 0.36$ & $2.42 \pm 0.35$ & 0.89 \\
DA RI & $0.87 \pm 0.10$ & $0.88 \pm 0.12$ & 0.74 \\
UA PSV cm/s & $39.8 \pm 10$ & $41.6 \pm 11$ & 0.28 \\
UA EDV cm/s & $16.1 \pm 6$ & $16.2 \pm 5$ & 0.85 \\
UA TAmax cm/s & $26.1 \pm 7.5$ & $26.9 \pm 7.1$ & 0.60 \\
UA PI & $0.96 \pm 0.25$ & $0.99 \pm 0.23$ & 0.55 \\
UA RI & $0.61 \pm 0.09$ & $0.62 \pm 0.08$ & 0.58 \\
MCA PSV cm/s & $33.3 \pm 11.5$ & $40.5 \pm 17$ & 0.02 \\
MCA EDV cm/s & $7.1 \pm 3.2$ & $8.7 \pm 5.3$ & 0.08 \\
MCA PI & $1.70 \pm 0.6$ & $1.72 \pm 0.7$ & 0.88 \\
MCA RI & $0.78 \pm 0.09$ & $0.80 \pm 0.08$ & 0.26 \\
\hline Abbeviatons PA pus & &
\end{tabular}

Abbreviations: PA pulmonary artery; $D A$ ductus arteriosus, UA umbilical artery; MCA middle cerebral artery; PSV peak systolic velocity; EDV end diastolic velocity; TAV time-averaged velocity; PI pulsatility index; $R I$ resistance index; TVI time velocity integral; TAmax time-averaged maximum velocity; $A T$ acceleration time; $E T$ ejection time; $A T: E T$ acceleration time to ejection time ratio; $\mathrm{cm}$ centimetres; $\mathrm{cm} / \mathrm{s}$ centimetres per second; $\mathrm{ms}$ millisecond. $\mathrm{MH}$ maternal hyperoxygenation. Values displayed as means \pm SD or median and $[\mathrm{IQR}]$

5.7 years, $p=0.29)$, maternal BMI $\left(29.3 \pm 4.8 \mathrm{~kg} / \mathrm{m}^{2}\right.$ vs. $\left.31.2 \pm 6.6 \mathrm{~kg} / \mathrm{m}^{2}, \mathrm{p}=0.29\right)$ or $\mathrm{GA}$ at the time of $\mathrm{MH}$ (35.3 \pm 2.2 weeks vs. $34.9 \pm 2.4$ weeks, $p=0.57$ ) (Fig. 4).

There were no significant changes in the peak systolic, end-diastolic, mean velocities or resistance indices across the DA following $\mathrm{MH}$. Fetal heart rate did not change significantly in response to $\mathrm{MH}(140 \pm 12 \mathrm{bpm}$ versus $136.8 \pm 8 \mathrm{bpm}, p=0.08$ ). There was a significant increase in MCA blood flow assessed using PSV, but not in MCA resistance indices. Intraobserver and interobserver variability of PA flow velocities (PI, RI) were low, with mean percent errors ranging from 4 to $6 \%$. High levels of ICC $(95 \% \mathrm{CI})$ were demonstrated (Supplementary Table 1).

The Caesarean delivery rate in this cohort was 54.3\% (25/46). The higher caesarean section rate and lower gestational age at delivery in the cohort is partly accounted for by the fact that twelve subjects $(26 \%, n=$ $12 / 46$ ) were long stay inpatients in the hospital due to a 
a)

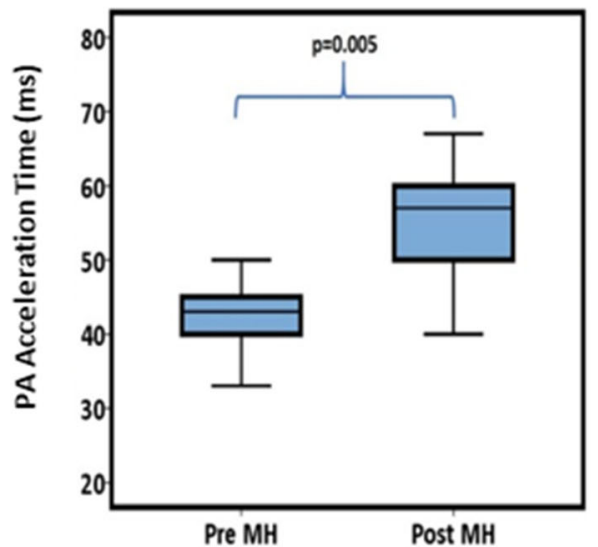

b)

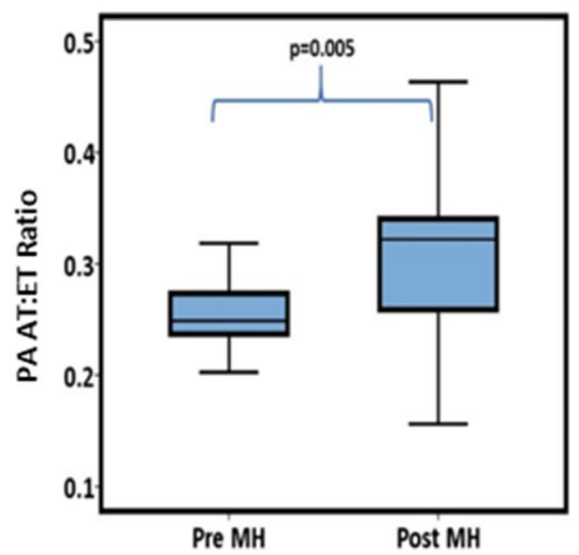

Fig. 3 Changes in PA AT: ET following maternal hyperoxygenation. a Pulmonary Artery Acceleration Time. b Pulmonary Artery AT:ET, Acceleration to Ejection Time Ratio. PA, pulmonary artery; Pre $\mathrm{MH}$, before maternal hyperoxygenation; Post $\mathrm{MH}$, following maternal hyperoxygneation; $\mathrm{ms}$, millisecond

diagnosis of placenta praevia, all of these patients underwent caesarean section at less than 38 weeks GA. A physical examination at birth was recorded as normal for all newborn subjects. A neonatal echocardiogram was performed on $74 \%(n=34 / 46)$ of recruited cases. Echocardiography was carried out at a median of $18 \mathrm{~h}$ [IQR 12-26] of life. Of the 12 neonates that did not undergo an echocardiogram, one had a fragile skin condition at birth and the test was deferred, one declined participation and ten infants were discharged home from the hospital before one of the study investigators could perform the echocardiogram. No neonate was diagnosed with persistent pulmonary hypertension. There was no difference in mean GA at delivery or in mean birthweight between the two groups (Table 3). Fetuses that responded to $\mathrm{MH}$ (a decrease PA PI > 10\% from baseline) were more likely to have a higher LVO (135 \pm 25 $\mathrm{mL} / \mathrm{kg} / \mathrm{min}$ verses $111 \pm 21 \mathrm{~mL} / \mathrm{Kg} / \mathrm{min}, \mathrm{p}=<0.01)$ and EF (54 $\pm 9 \%$ versus $47 \pm 7 \%, p=0.03$ ) within the first 24 $\mathrm{h}$ of life. These findings were not dependent on LV length or MV annular diameter but were related to an increase in MV inflow demonstrated by an increase in

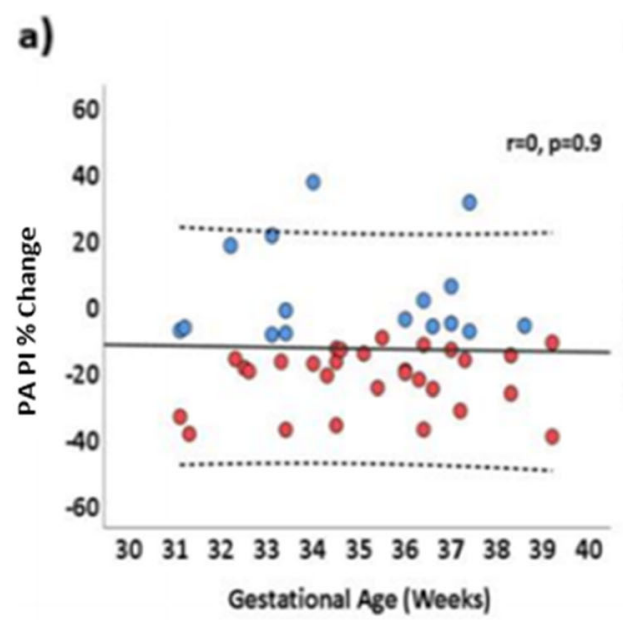

b)

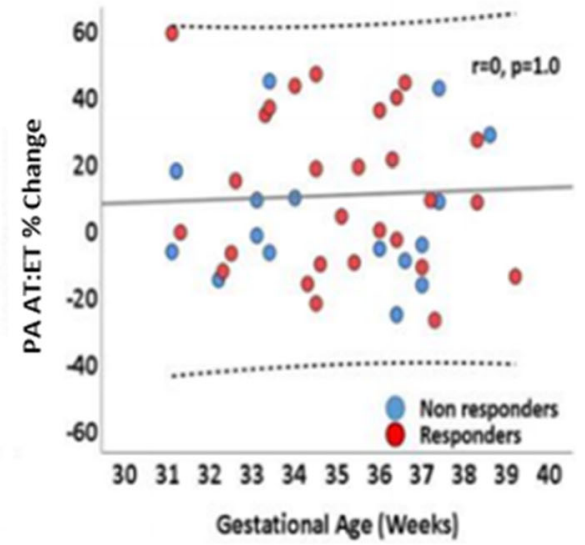

Fig. 4 Changes in fetal PA PI and PA AT:ET following maternal hyperoxygenation according to gestational age. a Fetal pulmonary artery pulsatility index percentage change in responders and non-responders to maternal hyperoxygenation according to gestational age. $\mathbf{b}$ Fetal pulmonary artery acceleration to ejection time ratio percentage change in responders and non-responders to maternal hyperoxygenation according to gestational age. $\mathrm{R}=0$ represents no correlation with gestational age, $p$ values not significant 
Table 3 Neonatal Data

\begin{tabular}{llll}
\hline & Responders $(\boldsymbol{n}=\mathbf{1 9})$ & Non-responders $(\boldsymbol{n}=\mathbf{1 5})$ & $\boldsymbol{p}$-value \\
\hline Gestation (weeks) & $37.4 \pm 1.9$ & $38.0 \pm 1.6$ & 0.32 \\
Birthweight (grams) & $3190 \pm 611$ & $3234 \pm 409$ & 0.80 \\
LV length (mm) & $28 \pm 4$ & $28 \pm 4$ & 0.88 \\
Mitral Valve Annular diameter (mm) & $8.6 \pm 1.4$ & $9.4 \pm 0.9$ & 0.08 \\
Ejection Fraction (\%) & $54 \pm 9$ & $47 \pm 7$ & 0.03 \\
Left Ventricular Output (mL/Kg/min) & $135 \pm 25$ & $111 \pm 21$ & $<0.01$ \\
Mitral Valve Inflow VTI & $8.6 \pm 1.6$ & $7.4 \pm 0.9$ & 0.01 \\
nPAAT (msec) & $78.6 \pm 26$ & $78.3 \pm 21$ & 0.53 \\
RV end systolic pressure (mmHg) & $18.6 \pm 12.2$ & $17.4 \pm 6.9$ & 0.81 \\
PDA characteristics (mm) & $2.6 \pm 1.3$ & $2.4 \pm 1.5$ & 0.74
\end{tabular}

Abbreviations: $L V$ left ventricle; VTI velocity time integral, $n P A A T$ neonatal pulmonary artery acceleration time; $R V$ right ventricle, $P D A$ patent ductus arteriosus; $m m$ millimetres; \% percentage; $\mathrm{mL} / \mathrm{Kg} / \mathrm{min}$ millilitres per kilogram per minute. All values reported are means $\pm \mathrm{SD}$

the MV velocity time integral $(8.6 \pm 1.6$ versus $7.4 \pm 0.9$, $p=0.01)$. There were no differences in nPAAT, RV end systolic pressures, or PDA characteristics between the two groups (Table 3).

The effect of $\mathrm{MH}$ on neonatal $\mathrm{LVO}$ was not dependent on mode of delivery (standardised $\beta=0.13, p=0.48$ ), GA at delivery (standardised $\beta=0.05, p=0.80$ ) or infant heart rate (standardised $\beta=-0.05, p=0.77$ ) at the time of the neonatal echocardiogram. However, neonatal LVO was dependent on the prenatal response to $\mathrm{MH}$ (standardised $\beta=0.51, p<0.01$ ). The neonatal EF was also not dependent on the mode of delivery (standardised $\beta=-0.17, p=0.29$ ) or GA at delivery (standardised $\beta=0.02, p=0.89$ ) but was dependent on the prenatal response to $\mathrm{MH}$ (standardised $\beta=0.34, p=$ 0.04 ) and on infant heart rate (standardised $\beta=-0.41$, $p=0.02$ ), (Table 4).

\section{Discussion}

We have demonstrated that maternal hyperoxygenation during the third trimester is associated with significant changes in fetal Doppler waveforms, characterised by a

Table 4 The Independent Effect of the response to Maternal Hyperoxygenation on Neonatal Left Ventricular Output (Model 1) and Ejection Fraction (Model 2)

\begin{tabular}{lllllll}
\hline Dependent Variable & Model 1: LVO & & & \multicolumn{2}{l}{ Model 2: EF } \\
\cline { 2 - 3 } Predictor Variables & Standardised $\boldsymbol{\beta}$ & $\mathbf{p}$ & & Standardised $\boldsymbol{\beta}$ & $\mathbf{p}$ \\
\hline MH Response & 0.51 & $<0.01$ & 0.34 & 0.04 \\
Mode of Delivery & 0.13 & 0.48 & -0.17 & 0.29 \\
Gestation at Delivery & 0.05 & 0.80 & 0.02 & 0.89 \\
Infant Heart Rate & -0.05 & 0.77 & -0.41 & 0.02 \\
\hline
\end{tabular}

Linear Regression Analysis assessing the independent effect of maternal hyperoxygenation response on neonatal left ventricular output (Model 1) and ejection fraction (Model 2).

Abbreviations: $L V O$, left ventricular output; $E F$, ejection fraction; $M H$,

maternal hyperoxygenation decrease in the PA PI and PA RI and an increase in the PA AT:ET. These changes did not occur at the expense of ductal constriction. These findings were not related to a change in the resistance indices of the uteroplacental circulation. Fetuses that were classified as responders to $\mathrm{MH}$ were more likely to have a higher left ventricular output and ejection fraction during the early neonatal period. The neonatal echocardiographic changes were due to an increase in mitral flow velocity (likely reflecting increased pulmonary blood flow) and not related to an increase in left ventricular size.

In the human fetus, blood flow velocity waveforms can be recorded from the right and left pulmonary arteries or from peripheral vessels within the lung. Analysis of the waveforms using ultrasound Doppler can be used to study the normal development of fetal lung circulation [39]. Doppler examination of blood flow in the main stem of the fetal pulmonary arteries is feasible and increases our insight into the lung perfusion of the human fetus. Mean decreases in PA PI following MH of between 18.0 and $21.2 \%$ have been previously described in normal fetuses [4]. A cut off level of $\geq 20 \%$ decrease in the PA PI from the baseline have been studied and deemed to demonstrate pulmonary reactivity $[4,40]$. However, there remains large individual variability [41, 42]. This variability can also be identified when the same fetus is serially assessed as gestation advances. In one study of normal fetuses, nearly one-third had a decrease in PA PI that was less than $20 \%$ after an initial positive oxygenation test earlier in gestation [13]. Values for reactivity in our study accounted for this variability and were based on a previous study where a decrease in PA PI of $\geq 10 \%$ from the baseline level was used to characterise a reactive test or positive responder [43].

The increase in fetal pulmonary blood flow following $\mathrm{MH}$ results in increased venous return to the left heart and this response increases with gestational age [44]. 
Studies indicate that a lack of vasoreactivity in response to $\mathrm{MH}$ may serve as a useful clinical tool in predicting lethal pulmonary hypoplasia in at-risk fetuses [40, 43]. The reactivity of the fetal pulmonary arteries to hyperoxygenation and its effect on neonatal cardiac function has not been established. Our study confirms previous findings of a significant decrease in fetal PA PI following MH [4, 40, 45]. Doppler echocardiography derived PA AT correlates with invasively derived PA pressures and PVR in children [46]. We have also demonstrated an increase in fetal PA AT:ET following $\mathrm{MH}$, indicating a fall in PVR. These data support previous reports in animal and human studies that a decrease in the pulmonary vascular impedance during $\mathrm{MH}$ is not caused by a constriction of the DA [4, 27, 47].

The effects of $\mathrm{MH}$ on fetal haemodynamic indices are limited, owing to a relatively high fetal umbilical vein oxygen saturation during normoxia, due to the high oxygen affinity of fetal haemoglobin [48]. Maternal hyperoxygenation has been shown to increase fetal partial pressures of oxygen in the umbilical artery and vein, as well as umbilical arterial oxygen saturations $[49,50]$. Our findings are in keeping with other studies where maternal hyperoxia induced no changes to umbilical artery Doppler resistance indices $[12,51]$.

The fetal ability to modify cardiac output is limited [7, 52]. Increases in preload, prenatally, have a minimal impact on fetal cardiac output, as the fetal heart is functioning at the peak of the Frank-Starling ventricular function curve [7]. There is a doubling of LVO in normal fetuses, within the first hour of life [53]. Increased pulmonary blood flow leads to a steady fall in PVR due to increased nitric oxide production. Within the first $24 \mathrm{~h}$ of life pulmonary arterial pressure has reached half that of systemic arterial pressure [6]. Our study demonstrated evidence of improved fetal MCA peak systolic velocity parameters in response to $\mathrm{MH}$, most likely due to the positive impact of improved pulmonary venous return on left ventricular preload and fetal left ventricular cardiac output.

All fetuses were normally grown and without structural abnormality at the time of recruitment. However, there were significant postnatal differences between those that responded to $\mathrm{MH}$ and those that did not. Those that responded appropriately to $\mathrm{MH}$, had signs of improved neonatal cardiac output with increased LV ejection fractions compared to poor responders as increased mitral valve flow velocities were observed in the responder group. It is likely that increased pulmonary blood flow due to an optimal postnatal pulmonary vasodilatation in the cohort observed to have the best response to $\mathrm{MH}$ prenatally was the basis of the measured values.

The most immediate and adverse adaptation of the fetal to neonatal transition is the persistence of high
PVR [54]. This can result in continued right to left or bidirectional shunting across the DA and/or foramen ovale leading to reduced pulmonary blood flow. Reduced pulmonary blood flow generates decreased pulmonary venous return and accordingly decreased LV preload and low LVO [55]. If this cycle continues, decreased organ perfusion will ensue, resulting in an increase in lactate, acidosis and hypoxia which are potent pulmonary vasoconstrictors and ultimately can lead to the development of pulmonary hypertension [56, 57]. The only predictor of a reduced neonatal LVO in our study was the fetal response to MH in utero. The LVO was not dependent on mode of delivery or GA at delivery and was not dependent on fetal heart rate. This interesting observation suggests that the neonatal compromise due to caesarean delivery is primarily a respiratory problem and that there is a cohort of infants who may be identified by $\mathrm{MH}$ prenatally, who would be predicted to have an increased vulnerability to deal with neonatal illness, due to a limited ability to achieve the pulmonary vasodilatation necessary to optimise LV preload and therefore achieve the increase in cardiac output demanded of the neonatal circulation.

\section{Strengths and limitations}

To our knowledge, this is the first study to compare the effects of MH with neonatal echocardiography evaluation, in normal pregnancies. All fetal Doppler measurements included in the study results were performed by a single operator (A.M). All neonatal echocardiography measurements were carried out by a single investigator who was blinded to the results of the fetal Doppler assessments (N.B).

We acknowledge the small sample size in our study. This warrants further exploration in a larger cohort to establish the ability of the fetal response to $\mathrm{MH}$ to predict postnatal adaptation of the pulmonary vascular circulation during the transition to neonatal life.

\section{Conclusion}

We have demonstrated that the extent of the response to maternal hyperoxygenation during fetal life may predict the rate of transition to the neonatal circulation, during the early neonatal period. Our study suggests that the prenatal hyperoxygenation test may offer the potential to predict an optimal adaptation to postnatal life, as evidenced by rapid postnatal reduction in pulmonary vascular resistance increasing measured cardiac output. The clinical implications of these findings require further investigation particularly in the context of pathologic conditions such as lung hypoplasia and congenital cardiac disease. 


\section{Supplementary Information}

The online version contains supplementary material available at https://doi. org/10.1186/s12884-020-03403-y.

Additional file 1: Supplementary Table S1. Intraobserver and Interobserver Repeatability of Pulmonary Artery Doppler Measurements

\section{Abbreviations}

PI: Pulsatility index; RI: Resistance index; AT: Acceleration time; ET: Ejection time; AT:ET: Acceleration to ejection time ratio; PA: Pulmonary artery; MH: Maternal hyperoxygenation; EF: Ejection fraction; LVO: left ventricular output; nPAAT: Neonatal pulmonary artery acceleration time; MV: Mitral valve; PVR: Pulmonary vascular resistance; GA: Gestational age; BMI: Body mass index; UA: Umbilical artery; MCA: Middle cerebral artery; DA: Ductus arteriosus; PSV: Peak systolic velocity; EDV: End diastolic velocity; TAV: Timeaveraged velocity; LV: Left ventricular; PDA: Patent ductus arteriosus; RV: Right ventricular; ICC: Intraclass correlation coefficient; TVI: Time velocity integral; TAmax: Time-averaged maximum velocity

\section{Acknowledgments}

The author would like to acknowledge the financial support from the Rotunda Foundation.

\section{Authors' contributions}

Conception and design: AM, FB. Development of methodology: AM, FB, AEK, OF. Acquisition of data: AM, CB, NB. Analysis and interpretation of data: AM, AEK, OF, FB. All Authors read and approved the manuscript.

\section{Funding}

This work was supported by the Rotunda Foundation (previously known as Friends of the Rotunda) through the Medical Research Charities Group (MRCG) joint funding scheme (MRCG-2013-19). The funding body played no role in the design of the study and collection, analysis, and interpretation of data and in writing the manuscript.

\section{Availability of data and materials}

The detailed datasets used and analysed during the study are available from the corresponding author on reasonable request.

\section{Ethics approval and consent to participate}

The trial was approved by the Health Products Regulation Authority of Ireland in August 2016. National Ethics approval for the trial was granted in September 2016. The clinical trial was assigned a EudraCT number of 2016003181-12. Each patient gave written consent for participation in the study.

\section{Consent for publication}

Not applicable.

\section{Competing interests}

The authors declare that they have no conflict of interests.

\section{Author details}

'Department of Obstetrics and Gynaecology, Royal College of Surgeons in Ireland, Rotunda Hospital, Dublin, Ireland. ${ }^{2}$ Department of Neonatology, Royal College of Surgeons in Ireland, Rotunda Hospital, Dublin, Ireland. ${ }^{3}$ Children's Health Ireland at Crumlin, Dublin, Ireland.

\section{Received: 25 June 2020 Accepted: 6 November 2020}

\section{Published online: 19 November 2020}

\section{References}

1. Goplerud JM, Delivoria-Papadopoulos M. Physiology of the placenta--gas exchange. Ann Clin Lab Sci. 1985;15(4):270-8.

2. Sharma V, Berkelhamer S, Lakshminrusimha S. Persistent pulmonary hypertension of the newborn. Matern Health Neonatol Perinatol. 2015;1:14

3. Rasanen J, Huhta JC, Weiner S, Wood DC, Ludomirski A. Fetal branch pulmonary arterial vascular impedance during the second half of pregnancy. Am J Obstet Gynecol. 1996;174(5):1441-9.

4. Rasanen J, Wood DC, Debbs RH, Cohen J, Weiner S, Huhta JC. Reactivity of the human fetal pulmonary circulation to maternal hyperoxygenation increases during the second half of pregnancy: a randomized study Circulation. 1998;97(3):257-62.

5. Prsa M, Sun L, van Amerom J, Yoo SJ, Grosse-Wortmann L, Jaeggi E, et al. Reference ranges of blood flow in the major vessels of the normal human fetal circulation at term by phase-contrast magnetic resonance imaging. Circ Cardiovasc Imaging. 2014;7(4):663-70.

6. Gao Y, Raj JU. Regulation of the pulmonary circulation in the fetus and newborn. Physiol Rev. 2010;90(4):1291-335.

7. Morton SU, Brodsky D. Fetal physiology and the transition to Extrauterine life. Clin Perinatol. 2016;43(3):395-407.

8. Lakshminrusimha S, Keszler M. Persistent pulmonary hypertension of the newborn. NeoReviews. 2015;16(12):e680-e92.

9. Vintzileos AM, Campbell WA, Rodis JF, Nochimson DJ, Pinette MG Petrikovsky BM. Comparison of six different ultrasonographic methods for predicting lethal fetal pulmonary hypoplasia. Am J Obstet Gynecol. 1989; 161(3):606-12.

10. Yoshimura S, Masuzaki H, Gotoh H, Fukuda H, Ishimaru T. Ultrasonographic prediction of lethal pulmonary hypoplasia: comparison of eight different ultrasonographic parameters. Am J Obstet Gynecol. 1996;175(2):477-83.

11. Ruano R, Martinovic J, Aubry MC, Dumez Y, Benachi A. Predicting pulmonary hypoplasia using the sonographic fetal lung volume to body weight ratio--how precise and accurate is it? Ultrasound Obstet Gynecol. 2006;28(7):958-62.

12. Simchen MJ, Tesler J, Azami T, Preiss D, Fedorko L, Goldszmidz E, et al. Effects of maternal hyperoxia with and without normocapnia in uteroplacental and fetal Doppler studies. Ultrasound Obstet Gynecol. 2005;26(5):495-9.

13. Dekoninck P, Lewi P, Done E, Richter J, Gucciardo L, Mieghem TV, et al. Sonographic evaluation of vascular pulmonary reactivity following oxygen administration in fetuses with normal lung development. Prenat Diagn. 2012;32(13):1300-4.

14. Lakshminrusimha $\mathrm{S}$. The pulmonary circulation in neonatal respiratory failure. Clin Perinatol. 2012;39(3):655-83.

15. Steinhorn RH. Neonatal pulmonary hypertension. Pediatr Crit Care Med. 2010;11(2 Suppl):S79-84.

16. Swanson JR, Sinkin RA. Transition from fetus to newborn. Pediatr Clin N Am. 2015:62(2):329-43.

17. Carlos WG, Baker MS, McPherson KA, Bosslet GT, Sood R, Torke AM. Smoking-related home oxygen burn injuries: continued cause for alarm. Respiration. 2016;91(2):151-5.

18. Albuquerque CA, Smith KR, Johnson C, Chao R, Harding R. Influence of maternal tobacco smoking during pregnancy on uterine, umbilical and fetal cerebral artery blood flows. Early Hum Dev. 2004:80(1):31-42.

19. Pringle PJ, Geary MP, Rodeck CH, Kingdom JC, Kayamba-Kay's S, Hindmarsh PC The influence of cigarette smoking on antenatal growth, birth size, and the insulin-like growth factor axis. J Clin Endocrinol Metab. 2005;90(5):2556-62.

20. Kho E, North R, Chan E, Stone P, Dekker G, McCowan L, et al. Changes in Doppler flow velocity waveforms and fetal size at 20 weeks gestation among cigarette smokers. BJOG Int J Obstet Gynaecol. 2009;116(10):1300-6.

21. Berkley E, Chauhan SP, Abuhamad A. Doppler assessment of the fetus with intrauterine growth restriction. Am J Obstet Gynecol. 2012;206(4):300-8.

22. Frusca T, Todros $T$, Lees $C$, Bilardo CM. Outcome in early-onset fetal growth restriction is best combining computerized fetal heart rate analysis with ductus venosus Doppler: insights from the trial of umbilical and fetal flow in Europe. Am J Obstet Gynecol. 2018;218(2s):S783-s9.

23. Turan OM, Turan S, Gungor S, Berg C, Moyano D, Gembruch U, et al. Progression of Doppler abnormalities in intrauterine growth restriction. Ultrasound Obstet Gynecol. 2008;32(2):160-7.

24. Sirico A, Rizzo G, Maruotti GM, Aiello E, Morlando M, Arduini D, et al. Does fetal macrosomia affect umbilical artery Doppler velocity waveforms in pregnancies complicated by gestational diabetes? J Matern Fetal Neonatal Med. 2016;29(20):3266-70.

25. Lam H, Leung WC, Lee CP, Lao TT. Relationship between cerebroplacental Doppler ratio and birth weight in postdates pregnancies. Ultrasound Obstet Gynecol. 2005;25(3):265-9.

26. McHugh A, El-Khuffash A, Bussmann N, Doherty A, Franklin O, Breathnach F. Hyperoxygenation in pregnancy exerts a more profound effect on cardiovascular hemodynamics than is observed in the nonpregnant state. Am J Obstet Gynecol. 2019;220(4):397.e1-8.

27. FCR M, Egan EA, Ferguson W, Lundgren CE. Development of pulmonary vascular response to oxygen. Am J Phys Heart Circ Phys. 1988;254(3):H542-H6. 
28. International Society of Ultrasound in O, Gynecology, Carvalho JS, Allan LD, Chaoul R, Copel JA, et al. ISUOG Practice Guidelines (updated): sonographic screening examination of the fetal heart. Ultrasound Obstet Gynecol. 2013;41(3):348-59.

29. de Boode WP, Singh Y, Gupta S, Austin T, Bohlin K, Dempsey E, et al. Recommendations for neonatologist performed echocardiography in Europe: consensus statement endorsed by European Society for Paediatric Research (ESPR) and European Society for Neonatology (ESN). Pediatr Res. 2016;80(4):465-71.

30. Groves AM, Singh Y, Dempsey E, Molnar Z, Austin T, El-Khuffash A, et al. Introduction to neonatologist-performed echocardiography. Pediatr Res. 2018;84(Suppl 1):1-12.

31. Sim J, Lewis M. The size of a pilot study for a clinical trial should be calculated in relation to considerations of precision and efficiency. J Clin Epidemiol. 2012;65(3):301-8.

32. Julious SA. Sample size of 12 per group rule of thumb for a pilot study. Pharm Stat. 2005;4(4):287-91.

33. Lancaster GA, Dodd S, Williamson PR. Design and analysis of pilot studies: recommendations for good practice. J Eval Clin Pract. 2004;10(2):307-12.

34. Moore CG, Carter RE, Nietert PJ, Stewart PW. Recommendations for planning pilot studies in clinical and translational research. Clin Transl Sci. 2011;4(5):332-7.

35. Staniszewska SDS, Matthews $\mathrm{R}$, et al. Reviewing progress in public involvement in NIHR research: developing and implementing a new vision for the future. BMJ Open. 2018;8:e017124.

36. Billingham SAM, Whitehead AL, Julious SA. An audit of sample sizes for pilot and feasibility trials being undertaken in the United Kingdom registered in the United Kingdom Clinical Research Network database. BMC Medical Research Methodology. 2013;13:104

37. Browne RH. On the use of a pilot sample for sample size determination. Stat Med. 1995;14(17):1933-40.

38. Hertzog MA. Considerations in determining sample size for pilot studies. Res Nurs Health. 2008;31(2):180-91.

39. Nicolaides KHRG, Hecher K, Ximenes R. Doppler in obstetrics. Fetal Medicine Founation. 2002:50-1.

40. Broth RE, Wood DC, Rasanen J, Sabogal JC, Komwilaisak R, Weiner S, et al. Prenatal prediction of lethal pulmonary hypoplasia: the hyperoxygenation test for pulmonary artery reactivity. Am J Obstet Gynecol. 2002;187(4):940-5.

41. Laudy JA, de Ridder MA, Wladimiroff JW. Human fetal pulmonary artery velocimetry: repeatability and normal values with emphasis on middle and distal pulmonary vessels. Ultrasound Obstet Gynecol. 2000;15(6):479-86.

42. Nicolaides KH, Campbell S, Bradley RJ, Bilardo CM, Soothill PW, Gibb D. Maternal oxygen therapy for intrauterine growth retardation. Lancet. 1987;1(8539):942-5.

43. Szwast A, Tian Z, McCann M, Donaghue D, Rychik J. Vasoreactive response to maternal hyperoxygenation in the fetus with hypoplastic left heart syndrome. Circ Cardiovasc Imaging. 2010;3(2):172-8.

44. Co-Vu J, Lopez-Colon D, Vyas HV, Weiner N, DeGroff C. Maternal hyperoxygenation: a potential therapy for congenital heart disease in the fetuses? A systematic review of the current literature. Echocardiography. 2017:34(12):1822-33.

45. Khatib N, Thaler I, Beloosesky R, Dabaja H, Ganem N, Abecassis P, et al. The effect of maternal hyperoxygenation on fetal circulatory system in normal growth and IUGR fetuses. What we can learn from this impact. J Matern Fetal Neonatal Med. 2018;31(7):914-8.

46. Levy PT, Patel MD, Groh G, Choudhry S, Murphy J, Holland MR, et al. Pulmonary artery acceleration time provides a reliable estimate of invasive pulmonary hemodynamics in children. J Am Soc Echocardiogr. 2016;29(11):1056-65.

47. Heymann MARA, Nies AS, Melmon KL. Bradykinin production associated with oxygenation of the fetal lamb. Circ Res. 1969;25:521-34.

48. Almström H, Sonesson S-E. Doppler echocardiographic assessment of fetal blood flow redistribution during maternal hyperoxygenation. Ultrasound Obstet Gynecol. 1996;8(4):256-61

49. Szwast A, Putt M, Gaynor JW, Licht DJ, Rychik J. Cerebrovascular response to maternal hyperoxygenation in fetuses with hypoplastic left heart syndrome depends on gestational age and baseline cerebrovascular resistance. Ultrasound Obstetr Gynecol. 2018;52(4):473-8.

50. Willcourt RJ, King JC, Queenan JT. Maternal oxygenation administration and the fetal transcutaneous PO2. Am J Obstet Gynecol. 1983;146(6):714-5.

51. Prior $T$, Kumar $S$. The impact of maternal hyper-oxygenation on foetoplacental blood flow. J Matern Fetal Neonatal Med. 2017;30(13):1563-8.

52. Keane JF, Lock JE, Fyler DC, Nadas AS. Nadas' pediatric cardiology. Philadelphia: Saunders; 2006.
53. Agata $Y$, Hiraishi S, Oguchi K, Misawa H, Horiguchi Y, Fujino N, et al. Changes in left ventricular output from fetal to early neonatal life. J Pediatr. 1991;119(3):441-5.

54. Singh Y. Echocardiographic Evaluation of Hemodynamics in Neonates and Children. Front Pediatr. 2017:5:201.

55. Pinsky MR. The right ventricle: interaction with the pulmonary circulation. Critical care (London, England). 2016;20(1):266.

56. Konduri GG, Kim UO. Advances in the diagnosis and management of persistent pulmonary hypertension of the newborn. Pediatr Clin North am. 2009:56(3):579-600. Table of Contents.

57. Dakshinamurti S. Pathophysiologic mechanisms of persistent pulmonary hypertension of the newborn. Pediatr Pulmonol. 2005;39(6):492-503.

\section{Publisher's Note}

Springer Nature remains neutral with regard to jurisdictional claims in published maps and institutional affiliations.
Ready to submit your research? Choose BMC and benefit from:

- fast, convenient online submission

- thorough peer review by experienced researchers in your field

- rapid publication on acceptance

- support for research data, including large and complex data types

- gold Open Access which fosters wider collaboration and increased citations

- maximum visibility for your research: over $100 \mathrm{M}$ website views per year

At BMC, research is always in progress.

Learn more biomedcentral.com/submissions 